\title{
Nursing and Assistance to Family Planning at the Primary Attention: the Contraception's Interface
}

Camila Almeida Neves de Oliveira1,2, Edilson Rodrigues de Lima ${ }^{3}$, Karízia Vilanova Andrade ${ }^{1,2}$, Eduarda Maria Duarte Rodrigues 1,4, Gláucia Margarida Bezerra Bispo 1,4, Eglídia Carla Figueirêdo Vidal1,2,4, Vívien Cunha Alves de Freitas 1,2, Priscila de Souza Aquino1,2, Lívia Parente Pinheiro Teodoro ${ }^{4}$, Adriana Alves da Silva ${ }^{1}$

\section{Abstract}

Introduction: The familiar planning is represented as an essential component at the Primary Attention to health, in which conforms the entrance door to the acting promotion and health prevention. Above all, it is noticed that the care at this sphere is marked by action and service fragmentation, without programming the activities by the team, unavailability of contraceptive Technologies, as by the lack of permanent education turned to those professionals. Given the above, the objective was to analyze the assistance according to the familiar planning conducted by the nurse at the Primary Attention under the integral health attention perspective.

Method: Qualitative Research, exploratory and descriptive, conducted with fifteen nurses at the primary care from Iguatu in Ceara, Brazil, in February and March 2015, through a semi-structured interview. The empirical data were organized through contents analysis.

Results: The knowledge about the familiar program planning assumptions, however, in practice, the assistance turned to the behavior-complains principle, given that some units were restricted to the method delivery, with perpetuation of curative actions, over the Professionals joint agenda elaboration.

Final Consideration: It is the need for effective union between the theory and practice at the nursing living at the family planning, When integrality, interdisciplinary and intersectoriality would justify the work process.
1 Ceara Federal Univesity, CE, Brazil.

2 Nursing Research Group Member on Sexual and Reprodutive Health, GESSARE. Ceara Federal University. Fortaleza, CE, Brazil.

3 Morada Nova City town hall. Morada Nova, CE, Brazil.

4 Cariri Regional University. Crato, CE, Brazil.

Contact information:

Camila Almeida Neves de Oliveira.

Address: Institutional Adress: Nursing Graduation Program, 1115 Alexandre Baraúna Street. Rodolfo Teófilo, ZIPE CODE 60430-160, Fortaleza, CE.

” camilaandeoliveira@gmail.com

Keywords

Family Planning;

Contraception; Nursing;

Primary Health Care. 


\section{Introduction}

In contemporary times, the public politics turned to the women health must have as perspective the multidimensionality that characterize it, requiring from the professionals and managers involved at the care of science in their role and attention to all the phase of the cycle of the women's life, proposing and running programs and actions which envisage the individual integrity and the care at health.

The familiar planning (FP) shows as an essential component to the Health Primary Attention (HPA), which shapes the gateway to promotion and health prevention actions. According to the provisions of Law $n^{\circ}$ 9263/96, the FP refers to the right that every citizen/ couple has the proper information, the qualified and expert assistance, access to resources and inputs that offer the possibility of electing independent, consciously or have no children, the amount, the spacing between them and choose the method that best fits your experience, free of discrimination, coercion and violence [1].

In Brazil, family planning activities have, over the years, gained importance, especially in 1983, through the Program of Integral Attention to Women's Health (PIAWH), characterized as a landmark on the world stage. This proposed reproductive health care for women, in contrast to isolated practices of family planning. In 2004, the National Policy for Integral Attention to Women's Health (NPIAWH), highlights among its working axes attention to family planning, in order to expand the guiding principles of integrity and promotion of women's health [2-3].

Today, with the guidance of comprehensive care through the Health Care Networks, the Network Stork [4], normalized by Ordinance $n^{\circ} 1.459$ of June 24, 2011 the Ministry of Health, has been following the conceptual break to see the woman not only as mother and mother, but as a subject of rights, with full service warranty on health beyond issues related to social reproduction and physiological.
In view of the network of comprehensive care, family planning happens a methodology of knowledge and health education to couples about reproduction, family participation, delimiting the role of women, father and son in this whole context and, consequently, on the implications of all this in the community. However, it is pertinent to note that the health services they cease emphasizing assistance only from the time the woman has already started their reproductive history, and there is the same commitment when related to women who have not gave birth, do not wish to experience motherhood or have difficulties to get pregnant [5].

It is noticed that the care in this area is marked by the fragmentation of activities and services without scheduling activities for staff, availability of contraceptive technologies and the lack of focused continuing education for professionals in question. It is noticeable that these users deserve more attention this health service, with emphasis on primary care, since it is realized as the system gateway and ordering of care from the perspective of health care networks [2].

Given the above, it becomes imperative to develop this study to understand the importance of actions taken by the professionals of health teams and to promote reflection of alternatives to these dilemmas experienced, in order that these individuals become subjects aware of their rights and duties and therefore, players of maintaining their own health.

Through such considerations came the following guiding questions: The family planning program is effectively implemented in the Basic Health Units? How does occur the teamwork process oriented attention to family planning? There is room for family planning in the work schedule of the team in an interdisciplinary way? What actions on family planning does staff in primary care unit develop? There is continuity of actions and regular monitoring of the woman/couple? 
Considering the complexity of the work in primary care, justifies this study that aims to analyze the regards assistance to family planning conducted by nurses in primary care from the perspective of comprehensive health care.

Thus, it is expected that the health work process overcome the fragmentation of activities and services, with the scope of the search for quality of care provided to the user and not just the demand for quantity of care, realizing that face this issue is critical to the strengthening and development of public policies that aim comprehensiveness of health care in contemporary society.

\section{Method}

To achieve the proposed objective, the research includes field research, exploratory-descriptive, qualitative approach [6], held in the city of Iguatu, Ceara, northeastern Brazil, in the period February-March 2015.

Study participants were 15 nurses of the Family Health Strategy (FHS), selected for convenience, after being duly informed about the objectives of the study, with the accepted registered in and Informed Consent. Inclusion criteria were: being a nurse of the Health Strategy of the municipality's Family; be responsible for coordinating the unit and carry out family planning consultation.

The choice of this location was due to the fact that the primary constitutes itself as the gateway to the municipal health network as well as the teams to count on a considerable number of women who enter the health service to service, thus enabling the development study. It is worth mentioning that, the unit coordinator nurse's election was made because the health unit has more than one nurse, because of the Multidisciplinary Residency Program implemented in the municipality.

Data collection was conducted through interviews using a semi-structured script, consisting of two parts: one focused on the characterization of the research subjects, and other pertinent to addressing the central theme of the study, involving questions concerning the knowledge of family planning expression, implementation of the program in the drive, the team work process and actions taken, as well as planning, scheduling and continuity of care.

The interviews took place by appointment by phone and place for the interview application was the application FHS unit, in nursing practice, providing a calm and reserved environment. The information was audio recorded with an average duration of 50 minutes and subsequently the content transcribed in full. To protect the identity of the interviewed nurses, they were identified by the letter $\mathrm{N}$, referring to the word nurse and the orderly number of interviews.

The interpretation of the data was through the content analysis technique, thematic modality [7] and the research was completed after the saturation of lines. After several readings of the material, we selected the relevant data and able to respond to the objective of the study, which were listed according to the most significant units of meaning contained in the expressions of the participants and defined the theme category of the study: Meaning Family Planning, which was split into two subcategories - Knowing the family planning program in primary care and Reflecting on family planning in team work process.

The development of the study met the national and international standards of ethics in research involving human subjects, according to the recommendations of Resolution $n^{\circ} 466 / 12$ of the National Health Council [6], it was approved by the Research Ethics Committee of the Public Health School of Ceara (ESP/CE) under Opinion 962.459.

\section{Results}

Through the assessment of the data, we attempted to analyze the regards assistance to family plan- 
ning operationalized by nurses within the primary care from the perspective of comprehensive health care, in which it obtained information about the meanings assigned to family planning in primary care, the main actions developed in this area, as well as about the team work process about family planning program in their areas ascribed, among others.

The study had the participation of 15 nurses from the Health Strategy of the municipality's Family. When referring to the categorization of subject apprehends that they belong mostly to females (93.75\%), They are predominantly between the age group of 25 to 30 years (46.66\%), are married [53.33\%), are catholic (80.00\%), your monthly personal remuneration varies between $2.000,00$ and $3.000,00846.66 \%$ ), have between $1-5$ years of academic training (40.00\%) and 1 to 5 years of experience in primary care $(53.33 \%)$, are postgraduates (86.66\%), have only one job (53.33\%) and employment is effective (80.00\%).

\section{(Re) meaning the family planning}

In order to understand what they know and the meanings attributed to the issue of family planning, participants made explicit the importance of proper planning of the offspring is assuming today, as well as understand the magnitude of the theoretical definition, with the double approach, knowledge of the reality that this is inserted, the importance of the availability of contraceptive methods and the consequent option for what best fits into their daily lives.

As follows the lines below, you can see that the study subjects hold a satisfactory knowledge of the meanings attributed to family planning in primary care, turning to assistance for the expanded concept of health, which involves biopsychosocial aspects, with emphasis on the right and autonomy of the couple.
It is a health program which watched men and women, access to contraception, which allow you to plan your family choosing to have or not have children, the quantity, the interval between pregnancies and the most suitable method of choice.

Plan is to have the option to decide the best time for a particular event. With regard to family planning calls into question a responsible decision about his own life and the lives of children possible, for they can come at an ideal time, expected and well prepared.

Set of measures or actions aimed at controlling in the family, the desired number of children, birth time, to better adapt to the socioeconomic possibilities of the couple/woman.

It is important to note that to conceptualize a particular subject has the possibility to perform an analysis of the given situation and hence encourage the modification of habits and routines. In this context, it was learned that the meanings attributed to the theme are synchronized. The terms most commonly used over the discourses about the concept of family planning were: "Pregnancy prevention" and "life schedule," denoting contraception and conception, respectively.

Of the 15 participating nurses study 10 reported that family planning service found it deployed the unit under his direction, through medical consultations and nursing, as well as through conversation circles and educational lectures. However, most of the participants mentioned that there is in your monthly schedule a specific day for care, most often justified by the non-compliance of the user or tribulation of routine work, and these actions are only performed if there is a spontaneous demand i.e. there is no active search of these women. Let's look at the testimonials: 
It is not effectively implemented because there is indeed as it should. Women only seek the service to receive the contraceptive method to prevent children. But there is no demand to plan pregnancy and doesn't respect one day to the family UBS planning schedule.

Yes, at UBS where I work we have more than 150 women in family planning. The inputs are offered monthly. Those who can't go or won't go through consultation signed and left. The working out and has no way to attend the ACS deliver at home.

No, ACO given without had scheduling and conducting planning in child care and gynecological prevention.

N13.

It should be pointed out that the actions related to family planning in some units were restricted to the delivery of contraception, available in pharmacy without proper guidance on the proper use, contraindications and possible adverse reactions. yet emerged from the speeches that due to the routine of women and professional, the opportunity of carrying out family planning activities only occurs along the prenatal consultation, postpartum, child care and gynecological prevention.

Yes there is a spare day, but every day is carried out if necessary family planning. the approach is made at the time she seeks the post or in the prenatal or postpartum consultation.

I confess that because so many responsibilities to nurse family planning is a little loose. But I put a specific day each month. Individually attend only those who are with any complaints, questions, and so on.
In rural areas the service is mixed, i.e., there are no book specific days for certain appointments or programs. The approach is made in a straightforward manner.

Apprehends that these actions is based on spontaneous demand of women in seeking the service for guidance, so there is not in the monthly calendar a day when the/the user/to know you can look up service and when there is, this covers only complaintconduct. It is worth noting that the unit location in the countryside, was cited as an obstacle to the realization of actions in family planning, since the service is mixed and there is no day specification for scheduling appointments, as well as the problems were mentioned geographical and cultural, as the extensive coverage area and taboos, respectively.

\section{Knowing the family planning program in primary care}

Continuing, it is inferred that there is in the speeches perpetuating healing actions, so that only women who have a change in detected tests or conditions have warranted follow-up, i.e., health promotion actions little run between teams in study.

There is no right programming to perform actions aimed at women. Family planning ACS has an important role during the home visits they detect women or couple who does family planning and guide the search for UBS to start. The actions that are given continuity: monitoring of positive (HIV), women have changes in gynecological prevention and treatment and monitoring of patients with STD.

Medical and nursing consultations are conducted, as well as lectures, conversation circle in the waiting room, among other activities. There is no planning on the agenda in an interdisciplinary way, but it is an action to be studied. 
No, because hardly the couple returns to be evaluated the effectiveness of the result of the method used. If there are no complaints about the method used, we just managed to capture this woman and/or couple from demand the same UBS for other needs.

An important point was the importance of the participation of the Community Health Agent ( $\mathrm{CHA}$ ) in this process, given that for these are in constant contact with the community have a bond of trust and are the link between this and the health service, thereby facilitating the active pursuit of women of childbearing age defaulting. However, health care in primary care also is based on the ancient teachings, with the fragmentation of care by professional category, while it was fairly reported that there is no planning in an interdisciplinary manner agenda, which would facilitate the work process the team and consequently improve the attention to the user's health.

In my practice there is no specific number of queries, but it is a patient who had a reaction to any ACO, for example, it will return as soon as possible.

It depends on the method used, they usually spend every month, but when I'm in another point of support to aid delivery for up to three months without the woman pass me.

There is no definition of how many annual consultations must be made, but seeks to provide the opportunity for meeting this target audience [...].

The agenda is according to the demand and the need for them
According to delineate the lines above, there are not deployed in family health programming teams of health actions in family planning by the demands of the population, such as the planning of the need for annual consultations to serve the population under their responsibility. The service related to family planning is not prioritizing the development of a joint agenda of the professionals who make up the team, which would structure the main actions to be carried out during the month and year and sequentially help them organize their process work. Similarly, the emergence of these women is not feasible, since they exposed the difficulty of maintaining the continuous monitoring of this target audience, which can be explained due to the inadequate implementation of previous steps, with programming and service fragile.

\section{Reflecting on family planning in team work process}

The study subjects reported that the assistance occurs sporadically and, exposing the information regarding the available methods and then choosing the patient. It is important to expose that gynecological care was well explained in speeches, with guidance on the importance of conducting the preventive examinations for cervical cancer, mammography and ultrasound annually, as well as a healthy lifestyle with proper nutrition, regular practice physical activity and reducing smoking.

We present the methods available and the patient chooses.

[...] is not a consultation, an initial assessment to survey the health of the woman with respect to age, varicose veins, if you smoke or not, if you have difficulty with some method... Nothing.

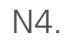


[...]lt aims to empower women on their decision of how and whether to form or expand their family and that they want to do, giving the chance that during planning are prepared (father and mother) for paternity / maternity; During family planning are addressed issues related to sexuality and gynecological health, as are issues that are close.

What I think that happens is the lack of interest as the lectures, training groups, and so on. They give more importance to the receipt of inputs. The methods available are not enough.

Before mentioned notes, the inputs available in health services in primary care are insufficient, by the range of effective contraceptive methods. Thus, demand, mostly refers to the receipt of this technology without proper knowledge about its proper use, which is compromising its effectiveness, as users do not understand the importance of participation in collective educational moments, however, a more intense approach about how such information is required are being worked by these professionals.

There are available all but the main yes, they are: condoms, oral contraceptives, monthly and quarterly injectable and the intra uterine device [...].

Often. Oral contraceptives and injectables.

We have oral contraceptives, injectables and condoms.

It apprehends that despite advances embodied obtained over the years, the team work process as regards the Family Planning Program also is rooted to fragmented care and curative. Thus, only a professional is charged and held accountable for certain actions to be accomplished without the involvement of the entire team, which goes against the principles of the Family Health Strategy, which involve interdisciplinary, with the reorganization of services and reorientation of professional practices in the logic of promoting the population's quality of life.

In reality there is little interest from other professionals and the nurse ends up being the professional that performs more actions to family planning.

The family planning program is more active in professional nurse. It is he who makes the monthly application of inputs, fills the chips to deliver the Pharmaceutical Assistance Center.

In this perspective, it is understood that because of the coordination of the health unit be nurses professional responsibility, this, in most cases, takes the performance of actions that should be the collective, and family planning is one of those. Thus, the other team members participate bit, generating a workload for nurses. However, despite being responsible for the care, he was quoted by the participants the importance of the need for training and updates pertaining to the topic, in order to qualify for assistance to community.

Many things improved. Today we have at UBS virtually all the methods recommended by the Ministry of Health, and in sufficient quantity. We realize that the right to sexual and reproductive health is being guaranteed, but professionals need constant training so that they can achieve a higher quality of care for men and women looking for health service. 
[...] now women have the opportunity to plan in this respect, and have their availability methods and professionals, most of whom are willing to guide and ask questions. One of the biggest barriers still found today are the religions and shame that people still have to deal with issues related to sexuality and family planning.

Assistance in family planning is still a little left out. We need more training, training in relation to the theme and availability of some necessary inputs.

According to the subjects in question, many positive changes have occurred over the program implementation process, such as free access to methods and the possibility of choice, despite the still present weaknesses, since the availability of all methods to the lack of adequate training of health professionals to perform a qualified service. It is necessary to incorporate in their work process of the importance of family planning takes nowadays, not only on the fertility and birth rates, but in reducing the number of unwanted pregnancies and abortions, the incidence of sexually transmitted diseases and consequently the rates of infant and maternal mortality.

\section{Discussion}

The promotion of women's health is not characterized a simple task, since it encompasses different factors throughout this intense process. Starting with the awareness of managers about their relevance to qualification of health indicators of women, with emphasis on sexual and reproductive health, not just maternal and child component, as well as the provision of professional, in order to qualify the assistance this population, and lastly the awareness of users linking to the team and consequently adherence to the outlined strategies.
In this context, throughout this study, we consider how operationalized assistance in family planning in primary care by nurses. So, the concept of family planning term was well explained by most respondents, under the comprehensive care point of view, however, the actions performed turn to the principle of complaint management, individual service and no interaction among the team members. The work process occurs through the demand of each unit, in which there is the search for woman / couple to service, forgetting to integrate the active search and limiting the program only the delivery of the contraceptive method available.

In this regard, assistance in family planning [9-10] it is not restricted to the availability or delivery of the contraceptive method to the user, since it refers to the right that every citizen/couple has the proper information, the qualified and expert assistance, access to resources and inputs that offer the possibility of reproductive planning.

Monitoring and guidance on the correct use of them represent key action, with a positive impact on the quality of life of users. Thus, the quality of the instruction to be shared by all professional will result in a better match the option, satisfaction and acceptability, continued use of birth control method, and consequently, reduction in fault indicator [11].

Similarly, most of the actions related to family planning described by the subjects in the study are carried out of their schedule, or during consultations Prenatal, Puerperium and Child Care, corroborating the findings of the literature, emphasizing that health services emphasize contraceptive care only from the moment that the woman has already started their reproductive trajectory [5].

The National Policy for Health Promotion, as regulated by Ordinance $n^{\circ} 687 / 2006$, outlines that health public actions should supplant curative and rehabilitative image, while also prioritize strategies for prevention and health promotion, with transformation of everyday life factors [12]. Above all, 
it is proposed that health interventions expand its design, having as object the problems and community health needs, its determinants, to involve the actions and health services in addition to the health unit walls, focusing on the living conditions of the population and benefiting from the growth of healthy choices by users in the territory where they live and work [13].

It is imperative that health professionals involved in reproductive planning assistance to hold the power to pervade the theoretical and scientific knowledge, to see women in all aspects and needs and take into account their cultural aspects regarding the choice of contraceptive method. It is the duty of professional help in decision making through service to press for the cordial welcome and respectful. Similarly, reproductive planning services require constant evaluation and improvement, considering the epidemiological and cultural characteristics of the community, in order to meet the couple's needs, considering the views on contraception skills development process [14].

The work of nurses in primary care is fundamental, since this is the professional who is more intense contact with the users, to know their reality, their fears and desires, being able to perform counseling actions, free- choice of contraceptive method, except the fragmented and isolated actions and emphasizing a multidisciplinary attention. The nurse, as a health educator, figures as a link between scientific knowledge and popular knowledge of the community, to address questions and share information relevant to the couple [15].

The nurse, being professional especially suited to guide the process of teaching and learning, helps each user obtain a satisfactory result, the address from the operation of the male and female reproductive systems, through the contraceptive methods as well as on autonomy of own fertility, as an active subject of knowledge. Family planning services require constant evaluation and improvement, considering the epidemiological and cultural characteris- tics of the community, in order to meet the couple's needs, considering the views on contraception skills development process [14].

In Brazil, the organization of public health services, professional training and the implementation of public policies distancing from the interdisciplinary point of view, being guided by the technical model and adding to this restricted inter-relationship between the team. Above all, family planning happens a methodology of knowledge and education to couples about reproduction, family involvement, and delimiting the role of women, father and son in this whole context and consequently on the impact of all this on community. In this case, it is necessary to recognize the context of life that surrounds this woman, then lay out and implement educational activities consistent with the need for health-assisted community and allow them to be enriched by individual and collective knowledge [5-15].

The National Humanization Policy, launched in 2003, assumes the value of different subjects involved in the health production process: users, workers and managers, promote the autonomy of users and increase the degree of co-responsibility, through the establishment of solidarity bonds and collective participation, without forgetting also the change of the care and management models, focusing on the needs of citizens, health production and own health work process [16].

It is noticeable that despite many efforts aimed at expansion of public policies on the promotion of women's health, the implementation of these actions is still a complex in the current reality of the health system, whereas minimum strategies related to sexual and reproductive health they are not yet developed in its entirety. The guidelines relating to women's health should pervade the mother-child approach to bridge the biologist care and leave for an equal assistance, comprehensive and human.

Given the above context, it is noted as limitations of this study it is impossible to make generaliza- 
tions about the issue of nurses' working process in family planning, given the qualitative nature of the research. Nevertheless, the uniqueness and depth of the highlighted aspects in place vis-à-vis a complex care scenario, under construction and needs more permanent education investment, through training, courses and deepening on the theme of family planning with professionals of the FHS, which routinely they are faced with new and multiple situations, and do not have the necessary support for the proper conduct of cases.

\section{Final Consideration}

The debates and international discussions about the women health in the contemporaneity figure around the integral attendance, interdisciplinary, and intersectorial in front of the fragmented actions and turned exclusively to the mother-children assistance. In this approach, this study permitted to reveal that the professionals understand the meaning of the familiar planning of the primary attention, as well as the importance of this role in front of the assistance of the users, under the point of view of the care integrality. However, in the practice the actions are fair made, turned essentially to a timely service, with the delivery of contraceptive methods available in unit.

One can show that the program is implemented in the units under study, however, it does not work in its entirety, since the process of work presented by professionals is based on individual and fragmented care, which is in line with the proposal health promotion. It is inferred that even assistance in family planning in the locus investigated materializes itself as the exclusive responsibility of the professional nurse, as the other team members just participate, and those who intend to participate does not own to accomplish such a task.

Through the data presented, it was possible to learn that programming, planning and follow-up activities are not performed by the team, while the- re is no interaction between professionals, case discussions by multidisciplinary group and team meetings with a view to improve the quality of care and assistance to the population, with a comprehensive and universal approach to health services, as well as the realization of continuing education to professionals who make up the team.

In this sense, it is expected to contribute not only with the services of the municipality, as well as the construction of knowledge and awareness of health professionals about the importance of health promotion, and health education as a permanent action in order to mitigate the information deficit and the consequent empowerment of women/couples. Therefore, it is suggested to carry out further studies to greater generalization of results.

\section{References}

1. Silva RM, Araújo KNC, Bastos LAC, Moura ERF. Planejamento familiar: significado para mulheres em idade reprodutiva. Ciência \& Saúde Coletiva. 2011; 16(5):2415-24.

2. Lopes ME, Silva SS, Moraes MLC, De Souza AP, Américo CF, Bezerra PAK. Conhecimento de enfermeiros sobre métodos contraceptivos no contexto do programa saúde da família. Rev. Enfermeria Global. N. 20. 2010

3. Cassiano ACM, Carlucci SEM, Gomes CF, Bennemann RM. Saúde materno infantil no Brasil: Evolução e programas desenvolvidos pelo ministério da saúde. Revista do Serviço Público Brasília. 2014; 65(2):227-44

4. Martinelli KG, Neto ETS, Gama SCN, Oliveira AE. Adequação do processo de assistência pré-natal segundo os critérios do Programa de Humanização do Pré-Natal e Nascimento e Rede Cegonha. Rev. Bras. Ginecol. Obstet. 2014; 36(2):56-64.

5. Santos JC, Freitas PM. Planejamento familiar na perspectiva do desenvolvimento. Ciência \& Saúde Coletiva. 2011; 16(3):181320.

6. Minayo MCS. O desafio do conhecimento: pesquisa qualitativa em saúde. 12 ed. São Paulo: HUCITEC, 2010.

7. Bardin L. Análise de conteúdo. 70. ed. 279 p. São Paulo: Almeida Brasil, 2011.

8. Ministério da Saúde (BR). Conselho Nacional de Saúde, Comissão Nacional de Ética em Pesquisa. Resolução No 466 de 12 de dezembro de 2012: aprova as diretrizes e normas regulamentadoras de pesquisa envolvendo seres humanos. Brasília: Ministério da Saúde; 2012. 
9. Guedes TG. Matriciamento da atenção em planejamento familiar de mulheres portadoras de transtorno mental. $123 \mathrm{p}$. Tese de Doutorado. Universidade Federal do Ceará. 2011.

10. Albuquerque GA, Villela WV. Uso do preservativo feminino como método contraceptivo: experiências de mulheres em uma unidade básica de saúde no município de Juazeiro do Norte CE. Revista APS Atenção Primária a Saúde. 2011; 14(2):185-96.

11. Rocha CMF, Dias SF, Gama AF. Conhecimentos sobre o uso de contraceptivos e prevenção de DST: a percepção de mulheres imigrantes. Cadernos de Saúde Pública. 2010; 26(1):1003-12.

12. Ministério da Saúde (BR).Secretaria de Atenção à Saúde. Política nacional de promoção da saúde. Brasília: Ministério da Saúde; 2006.

13. Ministério da Justiça (BR). Atenção integral na rede de saúde: módulo 5. 6. ed. 108 p. Secretaria Nacional de Políticas sobre Drogas (SENAD). Brasília: Ministério da Justiça; 2014.

14. Nicolau AIO, Dantas RC, Gadelha APP, Pinheiro APP. Conhecimento, atitude e prática de mulheres residentes no meio rural acerca dos métodos contraceptivos. Revista Eletrônica de Enfermagem. 2012; 14(1):164-70.

15. Santos JC, Freitas PM. Planejamento familiar na perspectiva do desenvolvimento. Ciência \& Saúde Coletiva. 2011; 16(3):181320.

16. Ministério da Saúde (BR). Secretaria de Atenção à Saúde. O HumanizaSus na Atenção Básica. Política Nacional de Humanização de Atenção e Gestão do SUS. Brasília: Ministério da Saúde; 2010.

Publish in International Archives of Medicine

International Archives of Medicine is an open access journal publishing articles encompassing all aspects of medical science and clinical practice. IAM is considered a megajournal with independent sections on all areas of medicine. IAM is a really international journal with authors and board members from all around the world. The journal is widely indexed and classified Q1 in category Medicine. 